\title{
Baccalaureate Nursing Students' Attitudes toward Patients with Mental Illness: Impact of Psychiatric Nursing and Mental Health Educational Experience
}

\author{
Marwa Abd El-Gawad Ahmed Mousa, Lecturer \\ Psychiatric Nursing and Mental Health, Faculty of Nursing, Alexandria University \\ Laila Helmy Ossman, Professor \\ Psychiatric Nursing and Mental Health, Faculty of Nursing, Alexandria University
}

\begin{abstract}
The general public and even many health professionals, including nurses, tend to hold a stereotyped image of those with mental illness. It is well documented that undergraduate nursing students can hold negative attitudes toward people with mental illness that can be positively impacted and manipulated by proper psychiatric nursing education. Objective: This study aimed to assess the change in baccalaureate nursing students' attitudes toward patients with mental illness before and after psychiatric nursing and mental health educational experience. Setting: The study was conducted at the Faculty of Nursing, Alexandria University. Subjects: Subjects comprised 184 students who where registered in the eighth semester of the academic year 2012-2013. Tools: Tools used to collect data for this study were a Student's Socio-demographic Characteristics and Previous Experience with Mental Illness Questionnaire and Community Attitudes toward the Mentally Ill (CAMI) Scale. Results: It was found that around two thirds of students showed improvement in their attitudes related to authoritarianism and social restrictiveness, while more than half showed improvement in benevolence and community mental health ideology after completing psychiatric nursing educational experience. Conclusion: Psychiatric nursing and mental health educational experience can bring significant improvements in students' attitudes toward patients with mental illness. Recommendations: Considering students' attitudes toward patients with mental illness while designing psychiatric nursing curricula at all Egyptian faculties of nursing is essential. Future researches are also required to study what other factors probably contributed to the change in these attitudes.
\end{abstract}

Keywords: Attitudes, mental illness, nursing students, psychiatric nursing educational experience.

\section{Introduction}

Individuals who suffer from mental illness have been devaluated and rejected throughout the history ${ }^{(1)}$. Subsequent public discrimination and prejudice against people with mental illnesses is ubiquitous and result in negative attitudes and beliefs ${ }^{(2,3,4)}$.

The term "attitude" encompasses knowledge, experiences, personal variables and emotions related to a particular topic ${ }^{(5)}$. Attitudes toward mental illness are individually based on specific stigmatizing attributions, emotional reactions, and behavioral responses that are related to that illness $^{(6)}$. It was argued that the general public and even many health professionals, including nurses, tend to hold a stereotyped image of those with mental illness. They believe that having a mental illness was due to some kind of personal weakness. Accordingly, mental illness is related to the persons own failings, such as weakness of character and morals, laziness, and lack of discipline and self-control. Other commonly held stereotypes include that people with mental illness are usually violent, 
dangerous, suspicious, undependable, unpredictable, unreliable, less intelligent, incompetent, can not work, and can never get better ${ }^{(2,7)}$.

Such misconceptions and the accompanying rejecting attitudes are often thought to be associated with worse consequences than the mental illness itself $^{(2,7,8)}$. Stigmatized patients with mental illnesses experience a vicious circle of rejection and discrimination which impedes psychiatric treatment seeking, erodes selfesteem, and limits patient's social network and work opportunities. These decrease the chances of recovery and rehabilitation ${ }^{(6,8)}$. More specifically, Morrison (2011) argued that nurses' discrimination against their patients may lead to inappropriate distancing, inadequate nursing care, and ineffective nursing interventions ${ }^{(9)}$. In this respect, psychiatric professionals including nurses need to be aware that their attitudes may have an effect on both their patients and the public ${ }^{(10)}$.

It is well documented that undergraduate nursing students can hold negative attitudes toward people with mental illness ${ }^{(11,12)}$. Yet, other research studies have concluded that those negative attitudes can be positively impacted and manipulated by proper nursing education $^{(9,12,13)}$. In this context, it was revealed that $66.6 \%$ of Egyptian students refused to work with a person known to have a psychiatric disorder. However, after the participation in mental health education project and active involvement with patients with mental illness, their stigmatizing attitudes were reduced ${ }^{(14)}$.

Programs preparing baccalaureate student nurses for the professional nursing role have the obligation to foster positive attitudes towards people with mental illness $^{(15)}$. A possible requirement for this action is to successfully pass a psychiatric nursing and mental health educational experience that focuses on decreasing healthcare disparities and stigma towards patients with psychiatric diagnoses ${ }^{(9,16)}$.
Whether or not student nurses will ultimately choose to become psychiatric nurses, their attitudes towards patients with mental illness have important implications for future practice. As future professionals in different health care services they will be required to manage a number of patients who are distressed by their illness or even have psychological problems ${ }^{(17,18)}$. They are important conveyors of attitudes through their roles when meeting patients, relatives and the general population ${ }^{(11)}$.

As future psychiatric nurses they will be in a unique position to make a positive impact on the public. They can affect change by their contact and sharing of knowledge with the community. They can also intervene through psycho-educational programs at the individual, family, and society levels in order to reduce negative attitudes toward people with mental illness $^{(19-21)}$. On that base, the role of education and clinical training in changing nursing students' attitudes toward patients with mental illness was addressed in the current study.

\section{Aim of the Study}

The current study aimed to assess the change in baccalaureate nursing students' attitudes toward patients with mental illness before and after psychiatric nursing and mental health educational experience.

\section{Research Question:}

Is there a change in baccalaureate nursing students' attitudes toward patients with mental illness before and after psychiatric nursing and mental health educational experience?

\section{Materials and Method}

\section{Materials}

Design: This research followed a crosssectional exploratory design.

Setting: The study was carried out at the Faculty of Nursing, Alexandria University, Egypt. The faculty has nine different 
scientific nursing departments, including the psychiatric nursing and mental health department.

The Faculty of Nursing follows the credit hours system in which the curricula are distributed along eight semesters, in addition to an internship year. One of the main courses taught is that of "psychiatric nursing and mental health", which is carried out in the seventh or eighth semester (depending on students' registration). The duration of this educational experience is 15 weeks. Clinical training is given 9 hours/week for 6 weeks and the theoretical contents are taught 3 hours/week for 15 weeks.

Subjects: The subjects of the study included all students in the eighth semester of the academic year 2012-2013, who were enrolled in the course of psychiatric nursing and mental health. Their total number amounted to 184 students.

Tools: Two tools were used to collect data:

Tool I: Student's Socio-demographic Characteristics and Previous Experience with Mental Illness Questionnaire

This tool was developed by the researchers based on relevant literature to elicit data related to student's code number, sex, age, residence, and previous exposure to academic psychiatric experience, work and/or coming in contact with patients having mental illness.

Tool II: Community Attitudes toward the Mentally Ill (CAMI) Scale

The CAMI is a 40-item scale developed by Taylor and Dear (1981) to assess people attitudes toward mental illness ${ }^{(22)}$. The scale included four subscales/attitudes; authoritarianism, (a view of the person with mental illness as someone inferior who requires coercive and authoritarian handling), benevolence (a moral paternalistic and sympathetic view of the person with mental illness), social restrictiveness (the belief that people with mental illness are a threat to society, should be avoided and must have restrictions placed on them), and community mental health ideology (the acceptance of mental health services and people with mental illness in the community, as well as having an optimistic view that mental illness is a disease like any other disease).

Each subscale contains ten statements; with half of them are negatively worded. Participants' responses are rated on a five-point Likert scale, with 1 denoting "strongly disagree" and 5 denoting "strongly agree". The score of each CAMI's subscale is ranging from 10 to 50. Lower scores on authoritarianism and social restrictiveness, and higher scores on benevolence and community mental health ideology subscales indicate a more positive overall attitude toward people with mental illness ${ }^{(22)}$.

The scale was successfully applied in previous studies $^{(9,23,24)}$. It was reported that it was valid and reliable (Cronbach's alpha $=0.90$ ). In addition, coefficient alpha reliabilities for its four subscales ranged from 0.68 to $0.88^{(22,25)}$.

\section{Method}

- Official permissions to conduct the study were obtained from the responsible authorities of the Faculty of Nursing, Alexandria University.

- Tool (I) was developed and tool (II) was translated into Arabic language.

- Study tools were presented to a jury composed of five experts in the psychiatric nursing field to test their content validity.

- Before embarking on the actual study a pilot study was carried out on 20 students from the fifth semester of the academic year 2012-2013 to ascertain the clarity and applicability of the study tools, and to identify obstacles that may be faced during data collection. The pilot study was conducted. Results of this pilot study revealed that tools were clear and applicable. 
- The internal consistency and reliability of tool (II) was tested using Cronbach's alpha coefficient test after being applied on 20 students from the fifth semester. The tool proved to be reliable (Cronbach's alpha $=0.819)$.

- The actual study started before the beginning of the psychiatric and mental health educational experience. The study subjects were approached on a group basis in their classroom and were invited to participate in the study. Then, tools were distributed to the students and explanations were given on how to fill them. This was done under the supervision of the researchers.

- $\quad$ By the end of the psychiatric nursing and mental health educational experience, the same process was repeated for tool (II).

\section{Ethical considerations:}

Throughout the study phases:

- Students' informed consent for voluntary participation in the study was obtained after explanation of its aim.

- The right to refuse to participate or to withdraw from the study was emphasized after reassuring students that their responses would have no impact on their grades.

- Data confidentiality was maintained and assured.

- The students' privacy was always respected.

\section{Statistical Analysis}

- Collected data were coded and transferred into specially designed formats suitable for computer feeding.

- Data entry, checking and verification were carried out. Frequency analysis, cross-tabulation and manual revision were all used to detect any errors.

- The Statistical Package for Social Sciences (SPSS) program, version 20.0 was utilized for both data presentation and statistical analysis of the results.

- The following statistical measures were used:

A. For descriptive presentations included: frequency, percentage, minimum, maximum, arithmetic mean, and standard deviation were used.

B. Statistical tests of significance:

- Mean change percent was used to calculate the changes in students' mean scores of attitudes before and after psychiatric nursing educational experience.

- Independent Student t-test was used to compare between two independent populations means.

- The levels of significance selected for this study were $\mathrm{p}$ equal to or less than 0.05 and 0.01 .

\section{Results}

Table (1) describes students' sociodemographic characteristics and previous experience with psychiatric studies, work and patients. The results indicated that $33.7 \%$ of subjects were males and $66.3 \%$ were females. Study subjects' age ranged between 20 and 25 years, with a mean age of $21.86 \pm 1.32$ years. Those living in rural areas constituted $62.5 \%$ of the studied subjects.

The table reveals that $77.2 \%$ of students had no previous academic psychiatric study, whereas those who obtained previous academic psychiatric study constituted $22.8 \%$ of the studied subjects. The period of their study ranged between one to four months, with a mean of $1.33 \pm 0.64$ months. 
It was also noticed that $92.9 \%$ of students did not previously work in a psychiatric field, while the minority $(7.12 \%)$ of them worked for one to eight months, with a mean of $4.03 \pm 2.50$ months.

Students who had previous personal contact/experience with patients having mental illness constituted $41.3 \%$ of the studied subjects. These patients were first degree relative $(6.6 \%)$, neighbor $(10.5 \%)$, second or third degree relative $(13.2 \%)$, friend or colleague $(28.9 \%)$, and/or homeless patients $(43.4 \%)$.

Table (2) describes the attitude changes among nursing students after the psychiatric nursing and mental health educational experience as measured by CAMI scale. It is worth mentioning here that any move on the subscales in the positive direction was considered as an improvement in the students' attitudes and vice versa. It was found that $69.6 \%, 51.6 \%, 65.2 \%$ and $53.3 \%$ of the students showed improvement in their attitudes related to authoritarianism, benevolence, social restrictiveness and community mental health ideology respectively. Those who revealed worsening attitudes were $21.2 \%, 15.8 \%$, $11.4 \%$ and $12.5 \%$ on the same subscales respectively. The rest reported no change, with community mental health ideology and benevolence being the most frequently unchanged $(34.2 \%$ and $32.6 \%$ respectively).

Table (3) presents the mean scores and mean change percent of the CAMI's subscales among students before and after the psychiatric nursing and mental health educational experience. It was evident that students' overall attitude toward people with mental illness improved after completing the educational experience as revealed by decrease in attitudes related to authoritarianism and social restrictiveness, and increase in attitudes related to benevolence and community mental health ideology. Significant variations were only noted in the mean scores of authoritarianism, benevolence, and social restrictiveness before and after the psychiatric nursing educational experience.

In relation to the subscale of authoritarianism, the mean score decreased from $33.40 \pm 2.91$ to $31.47 \pm 2.82$ after the educational experience. The mean score was significantly improved by $5.33 \pm 9.63$, $(\mathrm{t}=8.408, \mathrm{p}<0.001)$.

In the same direction, the mean score of the benevolence subscale increased from $28.99 \pm 3.458$ before the study to $30.28 \pm 2.137$ (improved by $1.70 \pm 9.66$ ) after passing through the educational experience, with a statistically significant difference $(\mathrm{t}=3.410, \mathrm{p}<0.001)$.

Concerning social restrictiveness subscale, the mean score was significantly improved by a percentage of $4.83 \pm 9.73$, where the mean score was $31.77 \pm 3.06$ before and decreased to $30.04 \pm 2.40$ after psychiatric nursing educational experience $(\mathrm{t}=7.808, \mathrm{p}<0.001)$.

In relation to community mental health ideology, its mean score was minimally increased from $32.30 \pm 3.03$ to $32.72 \pm 1.99$ after the educational experience. However, this improvement was not statistically significant $(\mathrm{t}=1.797, \mathrm{p}=0.074)$.

Table (4) presents relationships between students' socio-demographic characteristics and previous experience with psychiatric studies, work and patients, and their mean change percent on the CAMI's subscales. No statistically significant relationships were noticed between mean change percent of the studied subscales, and students' age, having a previous academic psychiatric study and the period of this study, previous work in psychiatric field and the period of this work, and previous personal contact with patients having mental illness ( $p>0.05)$.

On the other hand, a statistically significant relationship was detected between students' sex and their attitude of authoritarianism $(t=2.176, p=0.037)$. One can notice that male students improved by $3.33 \pm 9.37$, while female students improved by $9.59 \pm 7.88$ in the authoritarian attitude. 
Another statistically significant relationship ( $\mathrm{t}=2.387, \mathrm{p}=0.018)$ was found between students' residence and attitude of benevolence, where students who live in rural areas improved by $2.57 \pm 9.31$ and those who live in urban areas improved by $1.22 \pm 10.33$.

\section{Discussion}

Nursing students' attitudes are probably shaped by a variety of factors including gained knowledge and clinical training ${ }^{(11)}$. A growing body of literature suggests that direct clinical interactions with persons with mental illness along with an appropriate education seem to be an effective method of decreasing fear, increasing tolerance and changing negative attitudes, which potentially contribute to destigmatize mental illness ${ }^{(9,10,26)}$. Consequently, the current study questioned whether studying psychiatric nursing and mental health both theoretically and clinically improves baccalaureate nursing students' attitudes toward patients with mental illness. The study results showed positive responses to this question. This revealed by the improvements in students' attitudes related to authoritarianism, benevolence, social restrictiveness and community mental health ideology.

In this respect, it was pointed out that one of the important objectives of the psychiatric nursing education in baccalaureate programs is to help student nurses develop non-stigmatizing attitudes that enable them to provide effective care for people with different mental health problems in various health care settings ${ }^{(17)}$. Likewise, the course of psychiatric nursing and mental health at the Faculty of Nursing, Alexandria University aims at helping students develop and demonstrate positive attitudes towards patients with psychiatric problems $^{(27)}$.

Teaching concepts such as acceptance, genuine interest, empathy, unconditional positive regard, and respect, within the psychiatric nursing and mental health course can enable students to internalize such knowledge and skills needed to develop positive attitudes toward people with mental illness. In this way, this course may be regarded as an anti-stigma intervention which can enhance students' attitudes toward patients with mental illness. This explanation may be one of the main reasons for the improvements of students' attitudes. Findings of the current research are in harmony with those of previous studies reporting positive changes in CAMI's subscales after proper psychiatric education $^{(23,28,29)}$.

Another reason for this positive change may be attributed to the appropriate educational strategies and instructions provided by nursing educators. Their teaching methods, such as modeling and role playing, appear effective for decreasing students' anxiety, increasing tolerance, and developing more accepting attitudes. In this context, prior researches regarded the role of teaching and training in bringing about change in students' attitudes. They proposed that both knowledge gained during classroom teaching and experience gained during clinical training changed the students' attitudes in a less stigmatized $\operatorname{direction}^{(11,18,30)}$.

Gyllensten et al. (2011) argued that lack of knowledge influences attitudes towards patients with mental illness in a negative way $^{(20)}$. Yet, Seo and Kim (2010) found that gaining knowledge alone dose not change attitudes. However, education in conjunction with direct clinical exposure to patients with mental illness seem to be a key determinant of students' attitudes ${ }^{(24)}$. Increased personal contact with patients would improve students' reactions and the social distance and stigmatizing attitudes would, in turn, decrease $e^{(9,30,31)}$. In this context, it has been suggested that the clinical contact allows the student to create a meaningful alliance with the patient and alleviate fear in students ${ }^{(20)}$. This suggestion goes with the findings of the present study where mean scores of students' attitudes (authoritarianism, social restrictiveness, 
benevolence and community mental health ideology) changed in a favorable direction after terminating the educational experience of psychiatric nursing and mental health. It seems that the clinical practice which allows students to establish caring relationships with inpatients who have different psychological problems can help them to view patients as less dangerous, needing fewer restrictions, and having an illness that they are not responsible for. This in turn can lead to decrease the social distance and development of more accepting attitudes. Psychiatric nursing clinical experience of students in the present research might be an effective strategy to counteract stigma and produce fewer discriminatory reactions toward patients with mental illness. This explanation is also consistent with the findings of a previous research where most of students - in the beginning of their psychiatric clinical practicum - perceived patients with mental illness as aggressive, frightening and dangerous people who might hurt them, and questioned their own ability to help them. By the end of the rotation, none of these students expressed fear of the mentally ill and openly shared their admiration and respect for the patients whom they met on the hospital ${ }^{(32)}$.

Moreover, using self-understanding is emphasized as a therapeutic tool in psychiatric nursing while reaching these patients. Ongoing self-awareness helps student nurses to be aware and understand their own attitudes, feelings and behaviors, and accept others' attitudes and beliefs. Students are also invited to re-evaluate and readjust attitudes and beliefs periodically as they gain experience, while clinical instructors act as a role model, showing acceptance and tolerant attitudes toward patients with mental illness.

It is worth mentioning here that students' attitudinal improvements could be also attributed to the professional help combined with proper instructions and supervision provided by their instructors in psychiatric clinical areas. In this respect, it was noted that psychiatric nurse educators and clinical instructors can encourage more favorable attitudes among their students ${ }^{(7)}$.

However, the results of the current study are inconsistent with other researches which used the CAMI scale to measure attitudes toward people with mental illness after passing through psychiatric and mental health educational experience. The researchers attributed these results to the time allotted for the educational program which was relatively short and is not enough to change students' attitudes. They added that educational programs designed to change such negative attitudes need to be applied for a longer time and repeatedly ${ }^{(7,24)}$.

In addition, other researches failed to support the contention that positive attitudes develop as a result of appropriate education and practice ${ }^{(17,33)}$. One of these researches postulated that patient's symptoms and chronicity of psychotic disorders may increase students' anxiety and enforce negative attitudes toward these patients ${ }^{(33)}$. Another research claimed that the contact with patients can promote more positive attitudes if it is only voluntary ${ }^{(17)}$.

Yet, the results showed that still a good percentage of students in the present study either did not change their attitude or even had it worsened. One can suspect that the physical and psychosocial environment where students have their inpatient clinical experience might have a negative effect. As it may support certain stereotyped perceptions and negative attitudes for some students. Moreover, the duration of the clinical experience may be too short to affect attitudes formed over years and supported by common public beliefs and media.

Additionally, about three fifths, more than three quarters, the majority of students had no previous personal contact/experience with patients having mental illness, previous academic psychiatric experience, and did not previously work in a psychiatric field respectively. Those students came to study psychiatric nursing with some 
widespread public beliefs that people with mental illness are unreliable, dangerous, unpredictable and violent. The consequences of these beliefs can lead to increased unwillingness to accept the patients' right to live in the community and receive their community mental health services. This explanation appears partly true knowing that students achieved a minimal non-significant improvement in the attitude of community mental health ideology.

An important factor that can affect attitudes is the previous personal experience with people having mental illness. It has been suggested that the emotional contact and personal encounter with somebody (a friend or relative) who experiences mental illness may result in attitude change in a positive direction $^{(11,20,31)}$. People with such personal contact/experience have also been shown to be more willing to enter into helping relationships with those with mental illness and they generally adopt a more benevolent and accepting attitude towards them ${ }^{(22)}$. The results of other researches have indicated that people who previously came into contact with individuals having mental illness believe them to be less dangerous and thus fear them less than individuals who have not had previous contact with the mentally ill ${ }^{(29,30)}$. It was then expected that as a result of the exposure to an individual with mental illness, the participants would come to feel less fearful or insecure about patients with mental illness and would therefore report fewer negative attitudes toward these patients ${ }^{(23,26)}$. In contrast, the results of the current study revealed that there was no significant relationship between having previous personal experience with persons having mental illness (first degree relative, neighbor, second or third degree relative, friend, colleague, and/or homeless), and students' attitude changes.

Previous researchers also noted that obtaining previous academic psychiatric studies and practice can influence attitudes in a non-stigmatizing direction ${ }^{(10,20,26)}$. This means that having previous scientific psychiatric background, working in the psychiatric field and meeting with patients suffering from different kinds of mental problems prior to studying psychiatric nursing could be a good basis for improving the image of patients with mental illness. However, this note is not supported by the findings of the present study which indicated that changes in students' attitudes of authoritarianism, benevolence, social restrictiveness and community mental health ideology are not significantly related to having a previous academic psychiatric study.

A further important point that was emphasized in previous studies is that attitudes toward people with mental illness could be affected by sex. Hence, females have consistently shown less authoritarian attitude towards persons with mental illness and more benevolence and community mental health ideology than males ${ }^{(9,28)}$. This point could be supported by the results of the present study knowing that a statistically significant relationship was found between students' sex and their attitude of authoritarianism. Female students in the current study significantly changed (in a favorable direction) in their authoritarian attitude toward patients with mental illness than male students did. It appears that female students may possess more empathic tendency than male students. In this respect, it was assumed that empathic people are less likely to endorse stigma or to use more authoritarian and restrictive methods in dealing with people with mental illness ${ }^{(34)}$. In this respect, Morrison (2011) found that females were less authoritarian, more benevolent, and had more community mental health ideology than males ${ }^{(9)}$.

Speaking of the relationship between age and attitudes, previous studies found that younger students have more tendencies to develop positive attitudes than older students $^{(20,35)}$. Needless to say that all students in the present study were relatively young (between 20 and 25 years old), with very limited differences in age, and no 
statistically significant relationship was proved between students' age and their attitudes.

The place of residence seems to play a role in changing students' attitudes toward patients with mental illness. Hence, a statistically significant relationship was found between students' place of residence and their attitude of benevolence. Students who live in rural areas significantly improved in their benevolence attitude toward patients with mental illness than students who live in urban areas. Perhaps people who are living in small rural communities may have more close exposure to persons with different disabilities. This in turn may develop their benevolent view of patients with mental illness and enhance their accepting and positive attitudes toward these patients.

\section{Conclusion}

In the light of previous results, it could be concluded that theoretical and clinical psychiatric nursing and mental health educational experience can bring significant improvements in baccalaureate nursing students' attitudes toward patients with mental illness.

\section{Recommendations}

The followings are the main recommendations yielded by this study:

- Students' attitudes toward patients with mental illness should be considered while designing psychiatric nursing curricula at all Egyptian faculties of nursing.

- Community Attitudes toward Mental Illness scale can be a useful instrument in providing feedback to both students and nursing instructors regarding students' attitudes before the psychiatric nursing educational experience. Such information would increase students' self-awareness and guide instructors in changing negative attitudes.

- Future researches are required to study what other factors probably contributed to the change in these attitudes.

- Qualitative research approaches are recommended to gain different perspective on students' attitudes and experiences before and after psychiatric nursing and mental health education.

\section{Acknowledgment}

The researchers would like to express gratitude, thanks and appreciations to the students at the Faculty of Nursing, Alexandria University who participated in this study for their cooperation. 
Table (1): Students' socio-demographic characteristics and previous experience with psychiatric studies, work and patients.

\begin{tabular}{|c|c|c|}
\hline \multirow{2}{*}{ Variables } & \multicolumn{2}{|c|}{$($ n. $=184)$} \\
\hline & No. & $\%$ \\
\hline \multicolumn{3}{|l|}{ Sex } \\
\hline Male & 62 & 33.7 \\
\hline Female & 122 & 66.3 \\
\hline \multicolumn{3}{|l|}{ Age (in years) } \\
\hline $20<22$ & 165 & 89.7 \\
\hline $22-25$ & 19 & 10.3 \\
\hline Min. - Max. & \multirow{2}{*}{\multicolumn{2}{|c|}{$\begin{array}{l}20.0-25.0 \\
21.86 \pm 1.32\end{array}$}} \\
\hline Mean $\pm S D$ & & \\
\hline \multicolumn{3}{|l|}{ Residence } \\
\hline Urban & 69 & 37.5 \\
\hline Rural & 115 & 62.5 \\
\hline \multicolumn{3}{|l|}{ Having a previous academic psychiatric study } \\
\hline No & 142 & 77.2 \\
\hline Yes & 42 & 22.8 \\
\hline \multicolumn{3}{|l|}{$\begin{array}{l}\text { Period of previous academic psychiatric study (in months) } \\
((n .=42))\end{array}$} \\
\hline $1<2$ & 39 & 92.86 \\
\hline $2-4$ & 3 & 7.14 \\
\hline $\begin{array}{l}\text { Min. - Max. } \\
\text { Mean } \pm S D\end{array}$ & \multicolumn{2}{|c|}{$\begin{array}{l}1.0-4.0 \\
1.33 \pm 0.64\end{array}$} \\
\hline \multicolumn{3}{|l|}{ Previous work in a psychiatric field } \\
\hline No & 171 & 92.9 \\
\hline Yes & 13 & 7.12 \\
\hline \multicolumn{3}{|l|}{$\begin{array}{l}\text { Period of previous work in a psychiatric field (in months) } \\
\left(\left(n_{.}=13\right)\right)\end{array}$} \\
\hline $1<4$ & 9 & 69.23 \\
\hline $4-8$ & 4 & 30.77 \\
\hline $\begin{array}{l}\text { Min. }- \text { Max. } \\
\text { Mean } \pm S D\end{array}$ & \multicolumn{2}{|c|}{$\begin{array}{l}1.0-8.0 \\
4.03 \pm 2.50\end{array}$} \\
\hline \multicolumn{3}{|l|}{$\begin{array}{l}\text { Previous personal contact/experience with patients having } \\
\text { mental illness }\end{array}$} \\
\hline No & 108 & 58.7 \\
\hline Yes & 76 & 41.3 \\
\hline \multicolumn{3}{|l|}{ Relationship with this patient } \\
\hline First degree relative (father, mother, brother and/or sister) & 5 & $6.6^{\diamond}$ \\
\hline Neighbor & 8 & $10.5^{\diamond}$ \\
\hline Second or third degree relative & 10 & $13.2^{\diamond}$ \\
\hline Friend or colleague & 22 & $28.9^{\diamond}$ \\
\hline Homeless patient & 33 & $43.4^{\diamond}$ \\
\hline
\end{tabular}

\#: Frequencies are not mutually exclusive.

$\vartheta^{0}$ n.=76 (Students had previous personal contact/experience with patients having mental illness). 
Table (2): Attitude changes among nursing students after the psychiatric nursing and mental health educational experience.

\begin{tabular}{|c|c|c|c|c|c|c|}
\hline \multirow{3}{*}{ CAMI's subscales } & \multicolumn{6}{|c|}{$\begin{array}{c}\text { Degree of change in attitudes among the } \\
\text { studied students }(n .=184)\end{array}$} \\
\hline & \multicolumn{2}{|c|}{ Improved } & \multicolumn{2}{|c|}{ No Change } & \multicolumn{2}{|c|}{ Worsened } \\
\hline & No. & $\%$ & No. & $\%$ & No. & $\%$ \\
\hline Authoritarianism & 128 & 69.6 & 17 & 9.2 & 39 & 21.2 \\
\hline Benevolence & 95 & 51.6 & 60 & 32.6 & 29 & 15.8 \\
\hline Social restrictiveness & 120 & 65.2 & 43 & 23.4 & 21 & 11.4 \\
\hline $\begin{array}{l}\text { Community mental health } \\
\text { ideology }\end{array}$ & 98 & 53.3 & 63 & 34.2 & 23 & 12.5 \\
\hline
\end{tabular}

Table (3): The mean scores and mean change percent of the CAMI's subscales among students before and after psychiatric nursing and mental health educational experience.

\begin{tabular}{|c|c|c|c|}
\hline CAMI's subscales & $\begin{array}{c}\text { Before } \\
\text { Mean } \pm \text { SD }\end{array}$ & $\begin{array}{c}\text { After } \\
\text { Mean } \pm \text { SD }\end{array}$ & $\begin{array}{c}\text { Mean } \\
\text { Change } \% \pm \text { SD }\end{array}$ \\
\hline Authoritarianism & & & \multirow{3}{*}{$5.33 \pm 9.63$} \\
\hline Mean \pm SD & $33.40 \pm 2.91$ & $31.47 \pm 2.82$ & \\
\hline$t$-test $(p)$ & \multicolumn{2}{|c|}{$8.408 \times(<0.001)$} & \\
\hline Benevolence & & & \multirow{3}{*}{$1.70 \pm 9.66$} \\
\hline Mean \pm SD & $28.99 \pm 3.458$ & $30.28 \pm 2.137$ & \\
\hline$t$-test $(p)$ & \multicolumn{2}{|c|}{$3.410^{*}(<0.001)$} & \\
\hline Social restrictiveness & & & \multirow{3}{*}{$4.83 \pm 9.73$} \\
\hline Mean \pm SD & $31.77 \pm 3.06$ & $30.04 \pm 2.40$ & \\
\hline$t$-test $(p)$ & \multicolumn{2}{|c|}{$7.808^{*}(<0.001)$} & \\
\hline Community mental health ideology & & & \multirow{3}{*}{$2.09 \pm 10.61$} \\
\hline Mean \pm SD & $32.30 \pm 3.03$ & $32.72 \pm 1.99$ & \\
\hline$t$-test $(p)$ & \multicolumn{2}{|c|}{$1.797(0.074)$} & \\
\hline
\end{tabular}

$\mathrm{t}$ : Student t-test $\quad *$ : Statistically significant at $\mathrm{p} \leq 0.001$ 
Table (4): The relationship between students' socio-demographic characteristics and previous experience with psychiatric studies, work and patients, and their mean change percent on the CAMI's subscales after the educational experience.

\begin{tabular}{|c|c|c|c|c|}
\hline \multirow{2}{*}{$\begin{array}{|lr|}\text { Students' } \text { socio-demographic } \\
\text { characteristics r r and } \\
\text { experience with psychiatric } \\
\text { studies, work and patients }\end{array}$} & \multicolumn{4}{|c|}{ Mean Change $\% \pm$ SD } \\
\hline & Authoritarianism & Benevolence & $\begin{array}{c}\text { Social } \\
\text { Restrictiveness }\end{array}$ & $\begin{array}{c}\text { Community } \\
\text { Mental Health } \\
\text { Ideology } \\
\end{array}$ \\
\hline \multicolumn{5}{|l|}{ Sex } \\
\hline Male & $3.33 \pm 9.37$ & $1.33 \pm 8.40$ & $5.73 \pm 8.67$ & $2.31 \pm 9.18$ \\
\hline Female & $9.59 \pm 7.88$ & $1.93 \pm 10.39$ & $4.27 \pm 10.32$ & $1.95 \pm 11.44$ \\
\hline Test of significance $t(p)$ & $2.176^{*}(0.037)$ & $0.445(0.656)$ & $1.045(0.297)$ & $0.235(0.814)$ \\
\hline \multicolumn{5}{|l|}{ Age (in years) } \\
\hline $20<22$ & $5.41 \pm 9.69$ & $1.48 \pm 9.96$ & $5.15 \pm 9.94$ & $2.38 \pm 10.70$ \\
\hline $22-25$ & $4.69 \pm 9.37$ & $3.49 \pm 6.51$ & $2.18 \pm 7.37$ & $0.30 \pm 9.8$ \\
\hline Test of significance $t(p)$ & $0.329(0.742)$ & $1.280(0.209)$ & $1.356(0.177)$ & $1.119(0.264)$ \\
\hline \multicolumn{5}{|l|}{ Residence } \\
\hline Urban & $5.87 \pm 5.17$ & $1.22 \pm 10.33$ & $5.55 \pm 9.80$ & $1.22 \pm 11.79$ \\
\hline Rural & $5.17 \pm 9.86$ & $2.57 \pm 9.31$ & $4.61 \pm 9.72$ & $2.35 \pm 10.26$ \\
\hline Test of significance $t(p)$ & $0.435(0.664)$ & $2.387^{(0.018)}$ & $0.575(0.566)$ & $0.636(0.525)$ \\
\hline \multicolumn{5}{|l|}{$\begin{array}{l}\text { Having a previous academic } \\
\text { psychiatric study }\end{array}$} \\
\hline No & $5.01 \pm 9.76$ & $2.11 \pm 9.37$ & $4.75 \pm 10.14$ & $1.96 \pm 9.92$ \\
\hline Yes & $6.81 \pm 9.02$ & $0.20 \pm 10.85$ & $5.18 \pm 7.63$ & $2.69 \pm 13.55$ \\
\hline Test of significance $t(p)$ & $1.015(0.311)$ & $1.300(0.195)$ & $0.239(0.812)$ & $0.373(0.710)$ \\
\hline \multicolumn{5}{|l|}{$\begin{array}{l}\text { Period of previous academic } \\
\text { psychiatric study (in months) }\end{array}$} \\
\hline $1<2$ & $5.89 \pm 9.48$ & $2.0 \pm 11.82$ & $5.05 \pm 6.30$ & $2.06 \pm 16.12$ \\
\hline $2-4$ & $4.98 \pm 9.75$ & $1.25 \pm 10.07$ & $5.29 \pm 8.71$ & $3.19 \pm 11.50$ \\
\hline Test of significance $t(p)$ & $0.650(0.517)$ & $0.890(0.380)$ & $0.094(0.926)$ & $0.244(0.809)$ \\
\hline \multicolumn{5}{|l|}{$\begin{array}{l}\text { Previous work in psychiatric } \\
\text { field }\end{array}$} \\
\hline No & $5.14 \pm 9.46$ & $1.51 \pm 9.68$ & $4.68 \pm 10.06$ & $2.27 \pm 10.37$ \\
\hline Yes & $6.58 \pm 10.80$ & $2.95 \pm 9.59$ & $5.84 \pm 7.24$ & $0.89 \pm 12.21$ \\
\hline Test of significance $t(p)$ & $0.723(0.471)$ & $0.720(0.472)$ & $0.578(0.564)$ & $0.627(.532)$ \\
\hline \multicolumn{5}{|l|}{$\begin{array}{l}\text { Period of previous work in } \\
\text { psychiatric field (in months) }\end{array}$} \\
\hline $1<4$ & $9.41 \pm 11.13$ & $3.43 \pm 11.72$ & $5.01 \pm 8.45$ & $3.0 \pm 12.58$ \\
\hline $4-8$ & $8.76 \pm 11.05$ & $4.45 \pm 11.03$ & $6.81 \pm 6.72$ & $1.14 \pm 16.65$ \\
\hline Test of significance $t(p)$ & $1.875(0.175)$ & $0.333(0.720)$ & $0.138(0.872)$ & $0.260(0.773)$ \\
\hline \multicolumn{5}{|l|}{$\left|\begin{array}{lr}\text { Previous } & \text { personal } \\
\text { contact/experience } & \text { with } \\
\text { patients having mental illness }\end{array}\right|$} \\
\hline No & $5.69 \pm 11.20$ & $1.04 \pm 9.51$ & $5.62 \pm 10.09$ & $3.11 \pm 11.40$ \\
\hline Yes & $5.13 \pm 8.70$ & $2.06 \pm 9.76$ & $4.40 \pm 9.53$ & $1.53 \pm 10.16$ \\
\hline Test of significance $t(p)$ & $0.366(0.715)$ & $0.724(0.470)$ & $0.862(0.390)$ & $1.017(0.310)$ \\
\hline
\end{tabular}

t: Student t-test

*: Statistically significant at $\mathrm{p} \leq 0.05$ 


\section{References}

1. Stone A, Merlo L. Attitudes of college students toward mental illness stigma and the misuse of psychiatric medications. Journal of Clinical Psychiatry 2011; 72(2): 134-9.

2. Corrigan P. How stigma interferes with mental health care. American Psychologist 2004; 59(7): 614-25.

3. Michael S. Stigma. Advances in Psychiatric Treatment 2002; 8(5): 31723.

4. World Health Organization. Mental health: facing the challenges, building solutions. Report from the WHO European Ministerial Conference. 2005. Available at: http://www.euro.who.int/_data/assets/p df_file/0008/96452/E87301.pdf.

(Retrieved on: 12/9/2013).

5. Hollingshed A, Redlich F. Social class and mental illness. New York: John Wiley, 1958. In: Shyangwa P, Singh S, Khandelwal S. Knowledge and attitude about mental illness among nursing staff. Journal of Nepal Medical Association. 2003; 42: 27-31.

6. Halter M. The stigma of seeking care and depression. Archives of Psychiatric Nursing 2004; 18(5): 178-84.

7. Boey K. Medical students' attitudinal change associated with mental hospital experience. Singapore Medical Journal 1985; 26(1): 45-8.

8. Deka R. A study on attitude of college teachers and students of Guwahati towards the mentally ill. International Journal of Humanities and Social Science Invention 2013; 2(6): 13-5. Available at: http://www.ijhssi.org. (Retrieved on: 10/12/2013).

9. Morrison R. Nursing students' attitudes toward people with mental illness: Do they change after instruction and clinical exposure?. College of Nursing, University of South Florida, 2011. Available at: http://honors.usf.edu/documents/Thesis/U0 0977266.pdf. (Retrieved on: 1/6/2012).

10. Abd El-Meguid M, Rabie M, Bassim R. Stigma and attitude toward mentally ill among a sample of non-medical staff working in psychiatric hospitals. A transcultural study. The Arab Journal of Psychiatry 2011; 22(1): 55-64.

11. Markström U, Gyllensten A, Ulrika B, Björkman T, Brunt D, Hansson L, Leufstadius C, Sandlund M, Svensson B, Östman M, Eklund M. Attitudes towards mental illness among health care students at Swedish universities - A follow-up study after completed clinical placement. Nurse Education Today 2009; 29(6): 660-5.

12. Happell B. Comprehensive nursing education in Victoria: Rhetoric or reality? Journal of Psychiatric and Mental Health Nursing 2001; 8(6): 50716.

13. Bell A, Horsfall J, Goodin W. The mental health nursing clinical confidence scale: A tool for measuring undergraduate learning on mental health clinical placement. Australian and New Zealand Journal of Mental Health Nursing 1998; 7(4): 184-90.

14. Sartorius N, Schulze H. Reducing the stigma of mental illness: A report from a global program of the World Psychiatric Association. Cambridge: Cambridge University Press, 2005.

15. American Nurses Association [ANA]. Code of ethics for nurses with interpretive statements, 2011. Available at:

http://www.nursingworld.org/MainMenu Categories/EthicsStandards/CodeofEthic sforNurses/Code-of-Ethics.aspx. (Retrieved on: 10/12/2013).

16. American Association of Colleges of Nursing [AACN]. The essentials of 
baccalaureate education for professional nursing practice. Washington, DC, 2008. Available at:

http://www.aacn.nche.edu/educationresources/BaccEssentials08.pdf.

(Retrieved on: 10/12/2013).

17. Callaghan P, Shan C, Yu L, Ching L, Kwan T. Attitudes towards mental illness: testing the contact hypothesis among Chinese student nurses in Hong Kong. Journal of Advanced Nursing 1997; 26(1): 33-40.

18. Procter N, Hafner J. Student nurses' attitudes to psychiatry: the influence of training and personality. Journal of Advanced Nursing 1991; 16(7): 845-9.

19. Crabb J, Stewart R, Kokota D, Masson N, Chabunya S, Krishnadas R. Attitudes towards mental illness in Malawi: a cross-sectional survey. BMC Public Health 2012; 12: 541. Available at: http://www.biomedcentral.com/14712458/12/541 (Retrieved on: 25/7/2013).

20. Gyllensten A, Svensson B, Björkman T, Hansson L, Leufstadius C, Bejerholm U, Markström U, Östman M, Eklund M, Brunt D, Sandlund M. Attitudes in healthcare students towards mental illness - A pre- and post multicenter university program survey. The Internet Journal of Allied Health Sciences and Practice 2011; 9(3). Available at: http://ijahsp.nova.edu/articles/Vol9Num 3/pdf/Gyllensten.pdf. (Retrieved on: 10/5/2013).

21. Pinto-Foltz MD, Logsdon MC. Reducing stigma related to mental disorders: initiatives, interventions, and recommendations. Archives of Psychiatric Nursing 2009: 23(1): 32-40.

22. Taylor S, Dear M. Scaling community attitudes toward the mentally ill. Schizophrenia Bulletin 1981; 7(2): 22540.
23. Turner S. Reducing stigma toward the mentally ill: the impact of exposure versus information. Hanover College, 2007. Available at: http://psych.hanover.edu/researchThesis07/TurnerPaper.pdf. (Retrieved on: $13 / 8 / 2012$ ).

24. Seo M, Kim H. Effectiveness of an education program to reduce negative attitudes toward persons with mental illness using online media. Asian Nursing Research 2010; 4(2): 90-101.

25. Addison S, Thorpe S. Factors involved in the formation of attitudes towards those who are mentally ill. Social Psychiatry and Psychiatric Epidemiology 2004; 39(3): 228-34.

26. Yamada M, Shimosato S, Kazama M, Tanaka R, Panichkul Y, Supatra SLP, Meekanon P, Rojsanyakul W, Mori C. Investigation of nursing students' attitudes toward people with mental disorders: A comparative study of Thailand and Japan. International Bulletin of Yamanashi Medical University 2001, 18: 69-75. Available at: http://www.lib.yamanashi.ac.jp/igaku/m okuji/kiyou/kiyou 18/image/kiyou18/069t o075.pdf. (Retrieved on: 24/4/2013).

27. The Psychiatric Nursing and Mental Health Department. Psychiatric nursing and mental health. 3rd ed. Faculty of Nursing, Alexandria University, 2013.

28. Browne D. Attitudes of mental health professionals toward mental illness: Comparisons and predictors. Published Master Dissertation: Smith College School for Social Work, Northampton, Massachusetts, 2010. Available at: https://dspace.smith.edu/bitstream/handl e/11020/17124/DavidBrowneThesis.pdf. (Retrieved on: 5/8/2013).

29. Penny N, Kasar J, Sinay T. Student attitudes toward persons with mental Illness: the influence of course work and 
level I fieldwork. The American Journal of Occupational Therapy 2001; 55(2): 217-20.

30. Dawood E. Impact of clinical placement on nursing students' attitudes towards psychiatry. Journal of American Science, 2012; 8(2): 627-32. Available at: http://www.jofamericanscience.org/journ als/am/sci/am0802/087 8268am0802 62 7_632.pdf. (Retrieved on: 16/9/2013).

31. Gray A. Stigma in psychiatry. Journal of Royal Society of Medicine 2002; 95(2): 72-9.

32. Melrose S, Shapiro B. Students' perceptions of their psychiatric mental health clinical nursing experience: a personal construct theory exploration.
Journal of Advanced Nursing 1999; 30(6): 1451-8.

33. Mousa A. Challenges and learning issues facing nursing students during their psychiatric clinical training. Unpublished Master Thesis: Faculty of Nursing, Alexandria University, 2007.

34. Corrigan P, Watson A. The stigma of psychiatric disorders and the gender, ethnicity, and education of the perceiver. Community Mental Health Journal 2007; 43(5): 439-58.

35. Song L, Chang L, Shih C, Lin C, Yang M. Community attitudes towards the mentally ill: the results of a national survey of the Taiwanese population. International Journal of Social Psychiatry 2005; 51(2): 174-88. 